\title{
Editorial
}

\section{Psychosomatic Medicine in Germany: More Timely than Ever}

\author{
Stephan Zipfel ${ }^{a} \quad$ Wolfgang Herzog $^{b}$ Johannes Kruse ${ }^{c}$ Peter Henningsen ${ }^{d}$ \\ ${ }^{a}$ Department of Psychosomatic Medicine and Psychotherapy, University Medical Hospital Tübingen, \\ Tübingen, ${ }^{b}$ Department of General Internal Medicine and Psychosomatics, Heidelberg University Hospital, \\ Heidelberg, 'Department of Psychosomatic Medicine and Psychotherapy, University Hospital Giessen and Marburg, \\ Giessen and Marburg, and d Department of Psychosomatic Medicine and Psychotherapy, Klinikum rechts der Isar, \\ Technical University of Munich, Munich, Germany
}

\section{Introduction}

Psychosomatic medicine in Germany is not a synonym for consultation-liaison psychiatry but represents a comprehensive field [1] as well as a specialized medical discipline [2]. As a consequence, psychosomatic medicine in Germany has a larger institutional basis than in any other country. Like elsewhere, the German psychosomatic approach was originally rooted in the tradition of applying psychoanalysis to medicine - Franz Alexander was probably this method's most influential psychoanalyst. The fate of his primarily psychogenetic model was tied, as it was in Germany (Alexander Mitscherlich), to the rise and decline of psychoanalysis and psychoanalytic concepts like the specific conflict. German psychosomatic medicine, however, has another root, which was an independent forerunner of current models for bio-psychosocial medicine [3]. The so-called integrative psychosomatic medicine, as developed in internal medicine (Thure von Uexküll) and neurology (Viktor von Weizsäcker), conceptualized the interactions of mind, body, and environment in a different 'enactive and embodied' way: body and bodily symptoms are not mere manifestations of the 'theatre of the soul'. The body and its sensorimotor and other activities shape the mind as much as the other way round [4].
In Germany, psychosomatic medicine is not a subspecialty of psychiatry, although it has clear connections in terms of shared models, methods, and overlapping care for patients. At some places, most prominently in Heidelberg and Tübingen, departments of psychosomatic medicine are part of overarching departments for internal medicine. The institutional independence of psychosomatic medicine in Germany is largely due to German psychiatry resisting the integration of psychotherapy as a core method. Hence, psychosomatic medicine developed independently as an institutional and academic basis for psychotherapy in medicine and later for integrated care models.

The clinical core competency of German psychosomatic medicine is centered on integrated care for the following disorders: somatoform/functional disorders, eating disorders, somatopsychic disorders (including psycho-oncology, psychocardiology, neuropsychosomatics, and psychodiabetology), and psychotraumatology. An overlap with psychiatry exists in the fields of depressive, anxiety, and personality disorders.

The following presents a brief overview of the current state of institutionalization, research, and teaching in the field of German psychosomatic medicine.

\section{KARGER}

E-Mail karger@karger.com www.karger.com/pps
(C) 2016 S. Karger AG Basel

0033-3190/16/0855-0262\$39.50/0
Prof. Dr. Stephan Zipfel

Department of Psychosomatic Medicine and Psychotherapy University Medical Hospital Tübingen Otfried-Müller-Strasse 14, DE-72076 Tübingen (Germany)

E-Mail stephan.zipfel@med.uni-tuebingen.de 


\section{Psychosomatic Facilities and Structure}

The first psychosomatic inpatient hospital was opened in Berlin in 1927. Since then, numerous hospitals and departments developed specifically to address psychosomatic issues have been established across Germany. Actual data show that there are a total of 223 institutions covering more than 10,000 inpatient beds, with a mean duration of stay of 40 days. Of note, the number of inpatient beds in Germany nearly tripled this millennium. There has also been a steep increase of psychosomatic day-patient facilities in recent years.

The current types of psychosomatic hospital facilities are as follows:

1 Hospitals for psychosomatic medicine with a superregional coverage area. The hospitals often include specialized subunits (for example, eating disorders, PTSD, and chronic pain) comprising more than 200 beds.

2 Departments of psychosomatic medicine at general hospitals providing regional coverage. The departments administer a consultation-liaison service for the entire hospital but have limited inpatient facilities (936 beds).

3 Departments of psychosomatic medicine and psychotherapy as academic institutions at university hospitals. These departments are responsible for patient care (20-70 beds), teaching, and research (fig. 1).

4 Departments of psychosomatic medicine that are part of a psychiatric hospital (20-30 beds).

5 Consultation-liaison services for psychosomatic medicine at general and university hospitals (without own treatment unit).

Health insurance (public or private) covers treatment costs from a budget separate from the one for psychiatry. Costs for psychosomatic care are based on length of treatment rather than on the diagnosis-related group. This refunding system will probably change in the next few years.

Aside from the health insurance-covered hospital sector, there is a separate system of rehabilitation centers in Germany, which target the clinical areas of cardiology, oncology, neurology, orthopedics, and psychosomatic medicine. Their particular focus is on work-related aspects of disability prevention. Pension insurance covers the costs for these centers. There are 141 centers for psychosomatic medicine in this system, which provide about 16,000 additional inpatient beds with average treatment duration of 37 days [for more details, see 5].

Psychosomatic inpatient and day-patient treatment programs are mostly combined multimodal therapy pro-

Psychosomatic Medicine in Germany:

More Timely than Ever grams, combining psychotherapy in individual and group formats, oriented on treatment guidelines and best practice experiences. Very often, psychodynamic and cognitive-behavioral approaches are both used in a coherent overall framework. Based on the leading diagnosis, additional therapies, for example stress reduction techniques, physiotherapy, body psychotherapy, and creative therapies (art and/or music therapy) are often part of the combined treatment package. Problems in the interpersonal and psychosocial field are the major focus of family/partner-oriented treatments often supplemented by psychosocial skills training. As part of the new reimbursement system, the dosage of psychotherapy is monitored as a key input factor.

\section{Effectiveness of Integrated Care in German Psychosomatic Medicine}

Multimodal inpatient care in hospital departments for psychosomatic medicine has been shown to be effective in numerous naturalistic studies - RCTs are hardly possible to design to test such a complex intervention. A recent systematic review and meta-analysis on these studies [6] revealed a medium within-group effect size of $g=0.72$ for symptom change and 0.35 for change of interpersonal problems. However, there are now multisite RCTs in Germany, investigating the setting effects of day- and inpatient psychosomatic treatment in patients with a depressive disorder $[7,8]$.

The majority of psychosomatic departments and hospitals take part in stringent quality assurance programs in order to monitor their treatment programs and to provide transparency to the patients. In addition, registries were introduced in respective regions and states to provide outcome data on basic factors, for example duration of treatment, leading diagnosis, and number of comorbid disorders [9].

\section{Stages of Training and Specialization}

In 1993, the General Assembly of German Physicians voted for a three-level approach and, thus, a differentiated and stepped-care qualification training process for specializing in psychosomatic medicine and psychotherapy:

1 Psychosomatic basic care or 'Psychosomatische Grundversorgung' includes an 80-hour training comprising theoretical and clinical instruction, communi- 


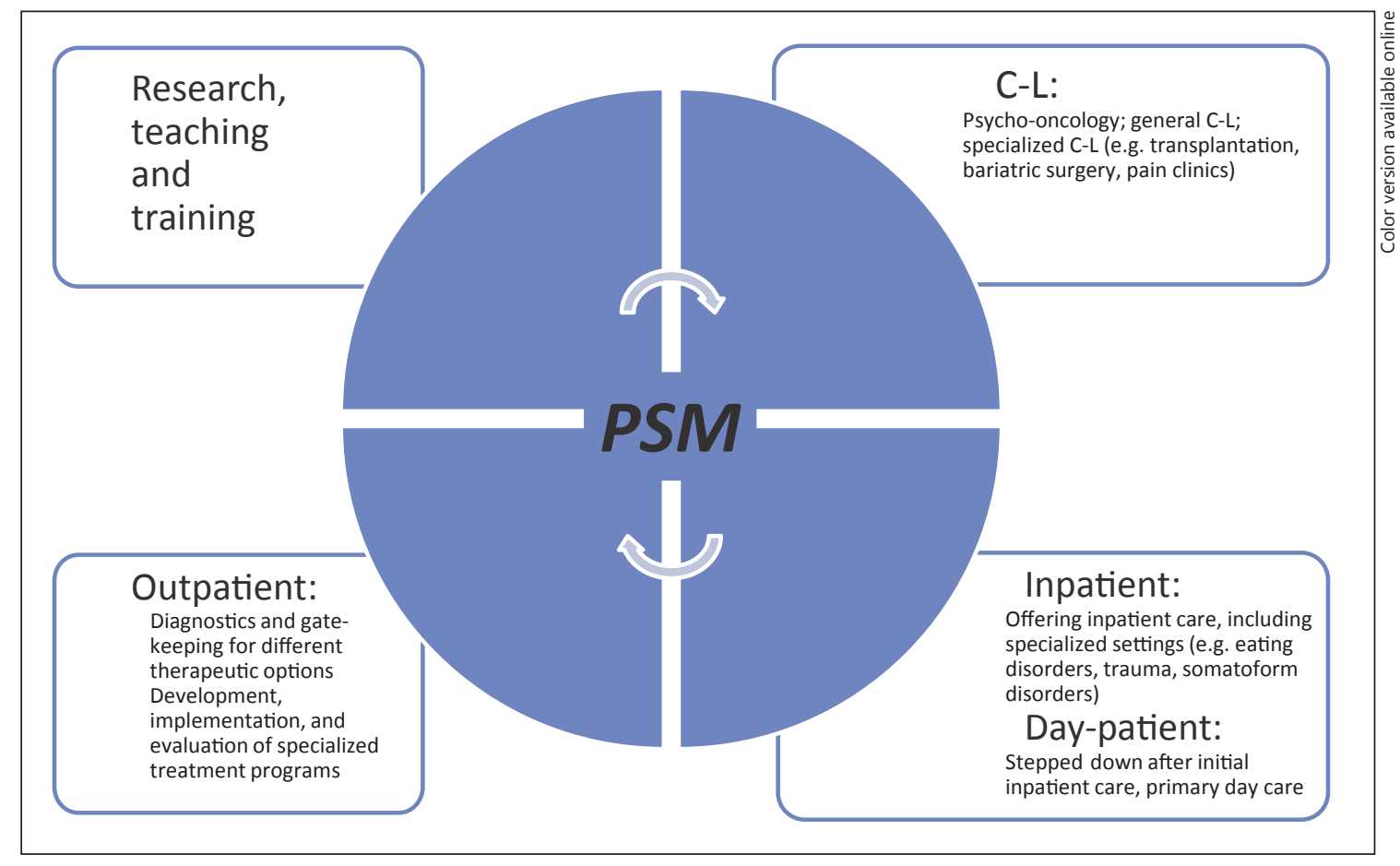

Fig. 1. Structure of an academic psychosomatic department (PSM) in Germany. C-L = Consultation-liaison; PSM = psychosomatics.

cation training with psychosomatic patients, and reflection of the doctor-patient relationship. All clinically practicing medical specialists can enroll in this training. Psychosomatic basic care is also an integral part of specialist training in general medicine and gynecology. About 35,000 general practitioners and 12,000 gynecologists have obtained this qualification [10].

2 A postgraduate degree in psychotherapy for those already holding a specialization degree (about 18,000 with an additional qualification in psychotherapy) [11]. The training is extra-occupational and conveys basic psychotherapeutic skills (120 h of supervised psychotherapy, $120 \mathrm{~h}$ of theoretical input, and personal therapy).

3 A 5-year specialization in psychosomatic medicine and psychotherapy (including 1 year each of internal medicine and psychiatry). This training comprises $1,500 \mathrm{~h}$ of supervised psychotherapy, $240 \mathrm{~h}$ of theoretical input, and personal therapy in both individual and group settings. The main emphasis is on the specialized psychotherapeutic and integrated psychosomatic treatment of patients with mental, psychoso- matic, somatopsychic, and stress disorders (for more details, see table 1). Among physicians who practice psychotherapy in Germany, a specialist in psychosomatic medicine and psychotherapy has received the most intensive psychotherapeutic training. Thus, he or she is the most qualified expert within the medical psychotherapeutic and psychosomatic care fields $(5,000$ specialists of psychosomatic medicine and psychotherapy) [11]. Additionally, there are about 11,000 psychiatrists and 5,600 neurologists [12]. In the outpatient sector, there are 3,058 specialists in psychosomatic medicine and psychotherapy as well as 3,900 specialists in psychiatry and psychotherapy, 1,972 neurologists, and 10,269 medical specialists with an additional psychotherapy certification (out of these, 3,493 are practicing mainly psychotherapy), summarizing a total of 21,312 medical trained doctors with a certification in psychotherapy (2014) [13] and a total of 16,664 psychologists with a specialization in psychotherapy [10]. In Germany, only medical doctors and psychologists are allowed to practice psychotherapy for adults. 
Table 1. Synopsis of the specialization curriculum in psychosomatic medicine in Germany

Specialization in psychosomatic medicine and psychotherapy

At least 5 years of full-time clinical training [ 3 years in psychosomatic medicine, 1 year in psychiatry, and 1 year in an additional clinical discipline (e.g. internal medicine), including theoretical, technical, and clinical training as well as supervision and personal therapy (see below)]

In total, $240 \mathrm{~h}$ of theory in psychosomatic medicine and psychotherapy [e.g. basics in psychodynamic-oriented psychotherapy (PDT) and CBT, psychopathology, psycho-diagnostic tests]

In total, $1,500 \mathrm{~h}$ of psychotherapeutic treatment have to be conducted alternatively in (a) PDT or (b) CBT, including individual or group-based supervision of at least every 4 th session

PDT-oriented track

6 individual psychotherapies of $50-120 \mathrm{~h} /$ patient

6 individual psychotherapies of $25-50 \mathrm{~h} /$ patient

4 focal, short-term therapies of $5-25 \mathrm{~h} /$ patient

2 couple therapies over a minimum of 10 sessions/couple

2 family therapies of $5-25$ sessions/family

$100 \mathrm{~h}$ of group psychotherapy (group size $6-9$ patients)

$150 \mathrm{~h}$ of psychodynamic-oriented personal psychotherapy and $70 \mathrm{~h}$ of personal psychodynamic-oriented group psychotherapy

CBT-oriented track

10 long-term individual CBT psychotherapies of 50 sessions/patient

10 short-term CBT-oriented psychotherapies with a total of $200 \mathrm{~h}$

4 couple and/or family therapies

6 group psychotherapies

$70 \times 2 \mathrm{~h}$ of CBT-oriented personal therapy in individual or group format

In addition, each trainee has to be trained in as follows: at least $32 \mathrm{~h}$ of stress reduction and relaxation

techniques (e.g. autogenic training), 10 cases of psycho-education in somatically ill patients, $35 \times 2 \mathrm{~h}$ of Balint groups or interactional group supervision, and 20 documented consultation-liaison cases

\section{Psychosomatic Medicine in Academic Teaching and Research}

In 1970, psychosomatic medicine became an obligatory subject in the medical school curriculum at the 37 official medical schools in Germany. Building on this advancement, the majority of the medical schools $(n=26)$ then decided to establish entire departments of psychosomatic medicine. The curricula of these departments not only cover the topic of psychosomatic medicine - its disorders, diagnostic techniques, and treatment methods but department members have actively created and implemented communication skills training as part of a competency-based medical curriculum. The departments have also been involved in the development, implementation, and evaluation of state-of-the-art teaching formats and continue to play an active role in the international medical education community [14-16].

In the first 2 decades following the nationwide introduction of psychosomatic medical departments in 1970, conducting empirical research was not a high priority.
Providing proper instruction was more pressing, and most chairs and professors were psychotherapeutic clinicians and theoreticians rather than empirical researchers. In 1986, the German Council of Science and Humanities (the central science advisory board to the government) criticized the state of research in the field of psychosomatic medicine. Since this wake-up call, things have changed gradually, but profoundly. Today, German psychosomatic medicine plays an active role in all areas of medical investigation - funded by federal and other third parties - be it clinical, health care, public health, or basic research.

\section{Clinical Research}

A particular strength of clinical research in psychosomatic medicine is the conceptualization, implementation, and evaluation of manualized disorder-oriented brief psychotherapies tested and demonstrated in different psychosomatic and mental disorders (e.g. the ANTOP study in anorexia nervosa $[17,18]$, the SPIRR-CAD study in depressed patients with coronary heart disease [19] and chronic heart failure [20], the PISO and SPE- 
CIAL studies in somatoform disorders [21, 22], the SOPHONET study in social phobia [23], the DAD study in diabetes $[24,25]$, and RCTs in depression $[7,26]$ and personality disorders [27]). Psycho-oncology is a fast-growing field of research interest in psychosomatic medicine, ranging from diagnostic to intervention studies [28-30]. While many of these therapies are psychodynamic [31, 32], the scope of treatment development is much broader and also covers CBT-oriented therapy and neuropsychologically informed treatment approaches. Most of these multisite RCTs were designed, implemented, and evaluated according to stringent and robust regulatory rules conforming to good clinical practice. In recent years, the psychotherapy community has worked to modernize web-based health treatments by developing and testing approaches that apply digital media (Interbed, Base, Restart [33-35]).

\section{Health Care and Public Health Research}

Health care research in psychosomatic medicine has a traditional, but by no means exclusive, focus on psychooncology. Typical topics include developing screening instruments [29], assessing the need for psycho-oncological support for patients and caregivers [36], and evaluating naturalistic interventions [37]. Another example of psychosomatic-based health care research is a trans-sectoral networking initiative in the large city of Hamburg, which brought together more than 60 partners from the government and the research, health care, and health industries (Psychenet [38]). In cooperation with other academic partners, the local university's Department of Psychosomatic Medicine coordinates and evaluates screening, networking, and therapeutic interventions in patients with eating and somatoform disorders [39].

Developing and coordinating evidence-based national guidelines on topics relevant to psychosomatic medicine, such as functional/somatoform or eating disorders, has been an important undertaking in recent years [22, 4044]. Researchers of psychosomatic medicine have also participated in several population-based cohorts in Germany (e.g. the Gutenberg Health Study in Mainz [45], the KORA study in Augsburg, and the ESTHER study in Heidelberg [46]). The studies provide epidemiological data on the interaction of different psychological, social, immunological, and other risk factors in the etiology and course of diabetes and cardiovascular and other chronic diseases. In a research world increasingly dominated by purely (systems) biological perspectives, these bio-psycho-social approaches are an important antidote against an all too strong reductionism.

\section{Basic Science}

In German psychosomatic research, there is a long tradition of basic science-related research [47], especially in the areas of mechanism-oriented [48], psychophysiological [49], life event-related, and stress-related research [49]. Contrarily, interest and expertise in animal-based or wet laboratory-based research is relatively recent. In the last decade, though, there has been a steep increase in the number of institutions with expertise in the field of neuroscience-related research paradigms, including neurocognitive [50] and neuroimaging approaches [51] and neuroimmunology [52]. Psychosomatic medicine research also plays a crucial role in national and international collaborative research networks, for example on nutrition medicine and eating disorders [50, 53-56], placebo and nocebo effects (DFG-funded research unit FOR 1328 [57-59]), and neural control of intestinal functions (NeuroGut in EU FP7 $[44,59,60]$ ).

\section{Conceptual Work}

Adapting bio-psycho-social concepts to modern medicine requires conceptual work. German psychosomatic medicine has contributed to two interdisciplinary European Union Marie Curie Training Networks (DISCOS and TESIS), where neuroscientists, psychologists, psychiatrists, and philosophers worked on translating current concepts of embodiment and enaction to clinical approaches to 'disorders of the embodied self [61].

\section{Organizations and National Congress}

There are two major psychosomatic medicine societies in Germany, which closely collaborate and share offices in Berlin. The first is the German College of Psychosomatic Medicine (DKPM) founded in 1974 by Thure von Uexküll and associates. It is an interdisciplinary scientific professional association for doctors, psychologists, and other professions (e.g. art therapists) and has about 450 members. Supported by the Swiss-based Carus Foundation, it runs and promotes postgraduate research-based training and advancement in all areas of psychosomatic medicine [62]. It has strong ties to other European, American, and Asian societies in the field of psychosomatic medicine. The second, the German Society for Psychosomatic Medicine and Medical Psychotherapy (DGPM), founded in 1992, is the medical association for the field of psychosomatic medicine and psychotherapy. It has about 1,300 members. Both organizations have their own Journal Citation Reports-listed journals (DKPM: Psychother 
Psychosom Med Psychol, Thieme publisher; DGPM: Z Psychosom Med, Hogrefe publisher).

Together, both societies (DGPM and DKPM) organize the annual conference on psychosomatic medicine and psychotherapy at the end of March each year at the Free University in Berlin. Over the last years an average of 1,100 participants and around 450 papers were presented in symposia or poster sessions including an English/international track. As a consequence, this conference is the biggest on psychosomatic medicine in Europe and the world and is not sponsored by the pharmaceutical sector [for recent discussion, see 63].

To conclude: combining its two traditions, German psychosomatic medicine has developed well over the last decades, benefitting from its institutional independence.
Clinically, disorder-oriented psychotherapy is a core method integrated with other modes of therapy; as a conceptual base for empirical research, nonreductionist accounts of the interactions of (sick) persons with their environment are most important. Therefore, the German model of psychosomatic medicine is a strong advocate for psychotherapy in medicine and thus more than ever a strong partner for a bio-psycho-social medicine in the 21 st century [64].

\section{Acknowledgment}

The authors want to dedicate this editorial to our colleague, friend, and teacher Prof. Peter Hahn, Heidelberg, who just turned 85 years.

\section{References}

1 Fava GA, Belaise C, Sonino N: Psychosomatic medicine is a comprehensive field, not a synonym for consultation liaison psychiatry. Curr Psychiatry Rep 2010;12:215-221.

2 Deter HC: Psychosomatic medicine and psychotherapy: on the historical development of a special field in Germany. Adv Psychosom Med 2004;26:181-189.

3 Herzog W, Beutel, M, Kruse J: Psychosomatische Medizin und Psychotherapie heute zur Lage des Fachgebietes in Deutschland. Stuttgart, Schattauer, 2014.

4 von Uexküll T: Integrierte Medizin als Gesamtkonzept der Heilkunde: Ein bio-psychosoziales Modell; in Adler RH, Joraschky P, Köhle K, Langewitz W, Söllner W, Wesiak W (eds): Psychosomatische Medizin: Theoretische Modelle und klinische Praxis. Munich, Elsevier, 2011;7:3-40.

5 Linden M: Psychosomatic inpatient rehabilitation: the German model. Psychother Psychosom 2014;83:205-212.

6 Liebherz S, Rabung S: Do patients'symptoms and interpersonal problems improve in psychotherapeutic hospital treatment in Germany? A systematic review and meta-analysis. PLoS One 2014;9:e105329.

7 Dinger U, Klipsch O, Kohling J, Ehrenthal JC, Nikendei C, Herzog W, Schauenburg H: Dayclinic and inpatient psychotherapy for depression (DIP-D): a randomized controlled pilot study in routine clinical care. Psychother Psychosom 2014;83:194-195.

8 Zeeck A, von Wietersheim J, Weiss H, Eduard Scheidt C, Volker A, Helesic A, EckhardtHenn A, Beutel M, Endorf K, Knoblauch J, Rochlitz P, Hartmann A: Symptom course in inpatient and day clinic treatment of depression: results from the INDDEP study. J Affect Disord 2015;187:35-44.
9 Probst T, von Heymann F, Zaudig M, Konermann J, Lahmann C, Loew T, Tritt K: The effectiveness of psychosomatic inpatient treatment - results of a multicenter follow-up study (in German). Z Psychosom Med Psychother 2009;55:409-420.

10 Kassenärztliche Bundesvereinigung: KBV NAoSHIP 2014. http://www.kbv.de/html/.

11 German Medical Association: Bundesärztekammer 2014. http://www.bundesaerztekammer.de/weitere-sprachen/english/german-medical-association/.

12 Bundespsychotherapeutenkammer: BPtK 2016. http://www.bptk.de/.

13 Statistik-Portal: Anzahl vertragsärztlicher Psychotherapeuten in Deutschland nach Bundesland im Jahr 2014. Statistik-Portal gbdndIS-D, 2014.

14 Keifenheim KE, Teufel M, Ip J, Speiser N, Leehr EJ, Zipfel S, Herrmann-Werner A: Teaching history taking to medical students: a systematic review. BMC Med Educ 2015;15: 159.

15 Weidner K, Herrmann-Lingen C, Herzog W, Junger J, Kruse J, Zipfel S, Kollner V: Learning objectives for psychosomatic medicine and psychotherapy in light of the national competency-based catalogue of learning objectives for medicine (NKLM). Z Psychosom Med Psychother 2015;61:275-288.

16 Maatouk-Burmann B, Ringel N, Spang J, Weiss C, Moltner A, Riemann U, Langewitz W, Schultz JH, Junger J: Improving patientcentered communication: results of a randomized controlled trial. Patient Educ Couns 2016;99:117-124.
17 Zipfel S, Wild B, Gross G, Friederich HC, Teufel M, Schellberg D, Giel KE, de Zwaan M, Dinkel A, Herpertz S, Burgmer M, Lowe B, Tagay S, von Wietersheim J, Zeeck A, SchadeBrittinger C, Schauenburg H, Herzog W; ANTOP study group: Focal psychodynamic therapy, cognitive behaviour therapy, and optimised treatment as usual in outpatients with anorexia nervosa (ANTOP study): randomised controlled trial. Lancet 2014;383: 127-137.

18 Zipfel S, Giel KE, Bulik CM, Hay P, Schmidt $\mathrm{U}$ : Anorexia nervosa: aetiology, assessment, and treatment. Lancet Psychiatry 2015;2: 1099-1111.

19 Albus C, Beutel ME, Deter HC, Fritzsche K, Hellmich M, Jordan J, Juenger J, Krauth C, Ladwig KH, Michal M, Mueck-Weymann M, Petrowski K, Pieske B, Ronel J, Soellner W, Waller C, Weber C, Herrmann-Lingen C: A stepwise psychotherapy intervention for reducing risk in coronary artery disease (SPIRRCAD) - rationale and design of a multicenter, randomized trial in depressed patients with CAD. J Psychosom Res 2011;71:215-222.

20 Lossnitzer N, Herzog W, Stork S, Wild B, Muller-Tasch T, Lehmkuhl E, Zugck C, Regitz-Zagrosek V, Pankuweit S, Maisch B, Ertl G, Gelbrich G, Angermann CE; Competence Network Heart Foundation: Incidence rates and predictors of major and minor depression in patients with heart failure. Int J Cardiol 2013;167:502-507.

21 Sattel H, Lahmann C, Gundel H, Guthrie E, Kruse J, Noll-Hussong M, Ohmann C, Ronel J, Sack M, Sauer N, Schneider G, Henningsen P: Brief psychodynamic interpersonal psychotherapy for patients with multisomatoform disorder: randomised controlled trial. Br J Psychiatry 2012;200:60-67. 
22 Henningsen P, Zipfel S, Herzog W: Management of functional somatic syndromes. Lancet 2007;369:946-955.

23 Leichsenring F, Salzer S, Beutel ME, Herpertz S, Hiller W, Hoyer J, Huesing J, Joraschky P, Nolting B, Poehlmann K, Ritter V, Stangier U, Strauss B, Stuhldreher N, Tefikow S, Teismann T, Willutzki U, Wiltink J, Leibing E: Psychodynamic therapy and cognitive-behavioral therapy in social anxiety disorder: a multicenter randomized controlled trial. Am J Psychiatry 2013;170:759-767.

24 Petrak F, Herpertz S, Albus C, Hermanns N, Hiemke C, Hiller W, Kronfeld K, Kruse J, Kulzer B, Ruckes C, Zahn D, Muller MJ: Cognitive behavioral therapy versus sertraline in patients with depression and poorly controlled diabetes: The Diabetes and Depression (DAD) study: a randomized controlled multicenter trial. Diabetes Care 2015;38:767-775.

25 Petrak F, Baumeister H, Skinner TC, Brown A, Holt RI: Depression and diabetes: treatment and health-care delivery. Lancet Diabetes Endocrinol 2015;3:472-485.

26 Leichsenring F, Schauenburg H: Empirically supported methods of short-term psychodynamic therapy in depression - towards an evidence-based unified protocol. J Affect Disord 2014;169:128-143.

27 Leichsenring F, Masuhr O, Jaeger U, Rabung S, Dally A, Dumpelmann M, Fricke-Neef C, Steinert C, Streeck U: Psychoanalytic-interactional therapy versus psychodynamic therapy by experts for personality disorders: a randomized controlled efficacy-effectiveness study in cluster B personality disorders. Psychother Psychosom 2016;85:71-80.

28 Haun MW, Sklenarova H, Villalobos M, Thomas M, Brechtel A, Lowe B, Herzog W, Hartmann M: Depression, anxiety and disease-related distress in couples affected by advanced lung cancer. Lung Cancer 2014;86: 274-280.

29 Schaeffeler N, Pfeiffer K, Ringwald J, Brucker S, Wallwiener M, Zipfel S, Teufel M: Assessing the need for psychooncological support: screening instruments in combination with patients' subjective evaluation may define psychooncological pathways. Psychooncology 2015;24:1784-1791.

30 Weissflog G, Brahler E, Leuteritz K, Barthel Y, Kuhnt S, Wiltink J, Zwerenz R, Beutel ME: Does psychodynamic short-term psychotherapy for depressed breast cancer patients also improve fatigue? Results from a randomized controlled trial. Breast Cancer Res Treat 2015; 152:581-588.

31 Leichsenring F, Leweke F, Klein S, Steinert C: The empirical status of psychodynamic psychotherapy - an update: Bambi's alive and kicking. Psychother Psychosom 2015;84:129-148.

32 Leichsenring F, Luyten P, Hilsenroth MJ, Abbass A, Barber JP, Keefe JR, Leweke F, Rabung S, Steinert C: Psychodynamic therapy meets evidence-based medicine: a systematic review using updated criteria. Lancet Psychiatry 2015;2:648-660.
33 Giel KE, Leehr EJ, Becker S, Herzog W, Junne F, Schmidt U, Zipfel S: Relapse prevention via videoconference for anorexia nervosa - findings from the restart pilot study. Psychother Psychosom 2015;84:381-383.

34 de Zwaan M, Herpertz S, Zipfel S, TuschenCaffier B, Friederich HC, Schmidt F, Gefeller O, Mayr A, Lam T, Schade-Brittinger C, Hilbert A: Interbed: Internet-based guided selfhelp for overweight and obese patients with full or subsyndromal binge eating disorder. A multicenter randomized controlled trial. Trials 2012;13:220.

35 Wild B, Hunnemeyer K, Sauer H, Hain B, Mack I, Schellberg D, Muller-Stich BP, Weiner R, Meile T, Rudofsky G, Konigsrainer A, Zipfel S, Herzog W, Teufel M: A 1-year videoconferencing-based psychoeducational group intervention following bariatric surgery: results of a randomized controlled study. Surg Obes Relat Dis 2015;11:1349-1360.

36 Sklenarova H, Krumpelmann A, Haun MW, Friederich HC, Huber J, Thomas M, Winkler EC, Herzog W, Hartmann M: When do we need to care about the caregiver? Supportive care needs, anxiety, and depression among informal caregivers of patients with cancer and cancer survivors. Cancer 2015;121:15131519.

37 Harter M, Buchholz A, Nicolai J, Reuter K, Komarahadi F, Kriston L, Kallinowski B, Eich $\mathrm{W}$, Bieber C: Shared decision making and the use of decision aids. Dtsch Arztebl Int 2015; 112:672-679.

38 Harter M, Kentgens M, Brandes A, Bock T, Dirmaier J, Erzberger M, Furstenberg W, Hillebrandt B, Karow A, von dem Knesebeck O, Konig HH, Lowe B, Meyer HJ, Romer G, Rouhiainen T, Scherer M, Thomasius R, Watzke B, Wegscheider K, Lambert M: Rationale and content of Psychenet: The Hamburg Network for Mental Health. Eur Arch Psychiatry Clin Neurosci 2012;262(suppl 2):S57S63.

39 Shedden-Mora MC, Gross B, Lau K, Gumz A, Wegscheider K, Lowe B: Collaborative stepped care for somatoform disorders: a prepost-intervention study in primary care. J Psychosom Res 2016;80:23-30.

40 Treasure J, Zipfel S, Micali N, Wade T, Stice E, Claudino A, Schmidt U, Frank GK, Bulik CM, Wentz E: Anorexia nervosa. Nat Rev Dis Primers 2015;1:15074

41 Hauser W, Urrutia G, Tort S, Uceyler N, Walitt B: Serotonin and noradrenaline reuptake inhibitors (SNRIs) for fibromyalgia syndrome. Cochrane Database Syst Rev 2013; 1:CD010292.

42 Konnopka A, Schaefert R, Heinrich S, Kaufmann C, Luppa M, Herzog W, Konig $\mathrm{HH}$ : Economics of medically unexplained symptoms: a systematic review of the literature. Psychother Psychosom 2012;81:265275.
43 Sattel H, Schaefert R, Hauser W, Herrmann M, Ronel J, Henningsen P, Hausteiner-Wiehle C: Treatment of non-specific, functional and somatoform bodily complaints (in German). Dtsch Med Wochenschr 2014;139: 602-607.

44 Enck P, Aziz Q, Barbara G, Farmer A, Fukudo S, Mayer AE, Niesler B, Quigley E, Rajilic-Stojanovicm M, Schemann M, Schwille-Kiuntke J, Simren M, Zipfel S, Spiller R: Irritable bowel syndrome. Nat Rev Dis Primers 2016;2:124.

45 Beutel ME, Wiltink J, Kirschner Y, Sinning C, Espinola-Klein C, Wild PS, Munzel T, Blettner M, Zwiener I, Lackner K, Michal M: History of depression but not current depression is associated with signs of atherosclerosis: data from the Gutenberg Health Study. Psychol Med 2014;44:919-925.

46 Schaefert R, Kaufmann C, Wild B, Schellberg D, Boelter R, Faber R, Szecsenyi J, Sauer N, Guthrie E, Herzog W: Specific collaborative group intervention for patients with medically unexplained symptoms in general practice: a cluster randomized controlled trial. Psychother Psychosom 2013;82:106-119.

47 Rajilic-Stojanovic M, Jonkers DM, Salonen A, Hanevik K, Raes J, Jalanka J, de Vos WM, Manichanh C, Golic N, Enck P, Philippou E, Iraqi FA, Clarke G, Spiller RC, Penders J: Intestinal microbiota and diet in IBS: causes, consequences, or epiphenomena? Am J Gastroenterol 2015;110:278-287.

48 Meyer T, Herrmann-Lingen C, Chavanon ML, Pieske B, Wachter R, Edelmann F: Plasma mid-regional pro-adrenomedullin levels are inversely associated with anxiety but unrelated to depression: results from the observational DIAST-CHF study in patients with cardiovascular risk factors. Psychoneuroendocrinology 2015;62:227-232.

49 Waller C, Bauersachs J, Hoppmann U, Hoch J, Krause S, Szabo F, Engler H, Rottler E, Herrmann-Lingen C, Gundel H: Blunted cortisol stress response and depression-induced hypocortisolism is related to inflammation in patients with CAD. J Am Coll Cardiol 2016; 67:1124-1126.

50 Giel KE, Friederich HC, Teufel M, Hautzinger M, Enck P, Zipfel S: Attentional processing of food pictures in individuals with anorexia nervosa - an eye-tracking study. Biol Psychiatry 2011;69:661-667.

51 Friederich HC, Wu M, Simon JJ, Herzog W: Neurocircuit function in eating disorders. Int J Eat Disord 2013;46:425-432.

52 Waller C, Wittfoth M, Fritzsche K, Timm L, Wittfoth-Schardt D, Rottler E, Heinrichs M, Buchheim A, Kiefer M, Gundel H: Attachment representation modulates oxytocin effects on the processing of own-child faces in fathers. Psychoneuroendocrinology 2015;62: 27-35.

53 Stengel A: Nesfatin-1 - more than a food intake regulatory peptide. Peptides 2015;72: 175-183. 
54 Brockmeyer T, Hahn C, Reetz C, Schmidt U, Friederich HC: Approach bias and cue reactivity towards food in people with high versus low levels of food craving. Appetite 2015;95: 197-202.

55 Simon JJ, Skunde M, Wu M, Schnell K, Herpertz SC, Bendszus M, Herzog W, Friederich HC: Neural dissociation of food- and moneyrelated reward processing using an abstract incentive delay task. Soc Cogn Affect Neurosci 2015;10:1113-1120.

56 Leehr EJ, Krohmer K, Schag K, Dresler T, Zipfel S, Giel KE: Emotion regulation model in binge eating disorder and obesity - a systematic review. Neurosci Biobehav Rev 2015;49: 125-134.
57 Enck P, Bingel U, Schedlowski M, Rief W: The placebo response in medicine: minimize, maximize or personalize? Nat Rev Drug Discov 2013;12:191-204.

58 Weimer K, Colloca L, Enck P: Placebo effects in psychiatry: mediators and moderators. Lancet Psychiatry 2015;2:246-257.

59 Elsenbruch S, Enck P: Placebo effects and their determinants in gastrointestinal disorders. Nat Rev Gastroenterol Hepatol 2015;12: 472-485.

60 Mack I, Cuntz U, Gramer C, Niedermaier S, Pohl C, Schwiertz A, Zimmermann K, Zipfel $S$, Enck P, Penders J: Weight gain in anorexia nervosa does not ameliorate the faecal microbiota, branched chain fatty acid profiles, and gastrointestinal complaints. Sci Rep 2016;6: 26752.
61 Fuchs T, Koch SC: Embodied affectivity: on moving and being moved. Front Psychol 2014;5:508

62 Lowe B, Hartmann M, Wild B, Nikendei C, Kroenke K, Niehoff D, Henningsen P, Zipfel S, Herzog W: Effectiveness of a 1-year resident training program in clinical research: a controlled before-and-after study. J Gen Intern Med 2008;23:122-128.

63 Fava GA: The hidden costs of financial conflicts of interest in medicine. Psychother Psychosom 2016;85:65-70.

64 Henningsen P: Still modern? Developing the biopsychosocial model for the 21st century. J Psychosom Res 2015;79:362-363. 